\title{
Oxygenate Reactions over PdCu and PdAg Catalysts: Distinguishing Electronic and Geometric Effects on Reactivity and Selectivity
}

Tanmayi Bathena, ${ }^{1}$ Truc Phung, ${ }^{1}$ Scott R. Svadlenak, ${ }^{1}$ Yu Liu, ${ }^{2}$ Lars C. Grabow, ${ }^{2,3}$ Konstantinos A. Goulas ${ }^{1 *}$

1. Oregon State University, School of Chemical, Biological and Environmental Engineering, Corvallis, OR 97331, USA

2. University of Houston, Department of Chemical and Biomolecular Engineering, Houston, TX 77204-4004, USA

3. Texas Center for Superconductivity at the University of Houston (TcSUH), Houston, TX 77204, USA

We investigate $\mathrm{Pd}_{x} \mathrm{Cu}_{y} / \mathrm{SiO}_{2}$ and $\mathrm{Pd}_{x} \mathrm{Ag}_{y} / \mathrm{SiO}_{2}$ catalysts in the context of oxygenate upgrading for biofuels. To this end, we measure the rates of decarbonylation and hydrogenation of butyraldehyde, the reactive intermediate for the industrially relevant Guerbet condensation, and correlate the selectivity and reactivity with the properties of the catalysts via a range of characterization efforts. Data obtained from EXAFS and XANES show that the bulk of the catalyst metallic nanoparticles is enriched in Pd, while the surface is enriched in $\mathrm{Cu}$ and $\mathrm{Ag}$. The data for $\mathrm{Pd}_{x} \mathrm{Cu}_{y} / \mathrm{SiO}_{2}$ show clear dominance of geometric (ensemble) effects on the selectivity. Conversely, the electronic (ligand) effects of alloying dominate over the reaction rate of the catalysts, as electron donation from $\mathrm{Cu}$ to $\mathrm{Pd}$ promotes the $\mathrm{Cu}$ and increases the desired (de)hydrogenation reactions. In contrast, in PdAg catalysts, the weaker electronic exchange, as indicated by Pd $\mathrm{L}_{\text {III }}$ XANES and theoretical calculations, is not sufficient to promote Ag, resulting in monotonic loss of activity with increasing $\mathrm{Ag}$ content and without selectivity improvement. We use the implications of these findings to provide valuable design principles for oxygenate catalysis and to discover a highly selective bifunctional catalyst system, comprised of $\mathrm{PdCu}_{3} / \mathrm{SiO}_{2}$ and $\mathrm{TiO}_{2}$ for the upgrading of ethanol to longer-chain oxygenates.

Keywords: Guerbet reaction, bimetallic catalysis, ethanol, decarbonylation, hydrogenation, XANES, palladium

*kostas.goulas@oregonstate.edu 


\section{Introduction}

Increased research in the usage of biofuels to combat global warming has led to the development of cutting-edge strategies to convert biomass to fuels and fuel additives. An essential step in converting biomass to biofuel is to upgrade its short-chain platform oxygenates to higher molecular weight compounds through $\mathrm{C}-\mathrm{C}$ bond coupling $[1,2]$.

Reactions such as ketonization [3, 4], aldol condensation[5], and the Guerbet reaction [6, 7], have garnered attention as they allow feasible pathways for the formation of C-C bonds [8]. In particular, the Guerbet reaction requires the activation of a $\mathrm{C}-\mathrm{H}$ bond in the reactant alcohol prior to a $\mathrm{C}-\mathrm{C}$ bond formation step involving the reactive aldehyde $[9,10]$. To this end, bifunctional catalysts comprising a metallic function and an oxide function are often used $[11,12]$. The activation of the $\mathrm{C}-\mathrm{H}$ bond takes place over the metal surface, while the C-C bond formation takes place over the oxide[13]. However, side reactions take place over the metallic part of the catalyst, such as the Tishchenko reaction (esterification) over Cu catalysts and $\mathrm{C}-\mathrm{C}$ bond scission reactions over Pt and $\mathrm{Pd}[3,14]$. Hence, it is important to investigate catalysts that favor the $\mathrm{C}-\mathrm{H}$ bond activation while preserving the carbon chain.

Currently, many bimetallic catalytic systems are investigated in the context of biomass upgrading $[15,16]$, given their unique catalytic properties that differ from those of their parents, often in nonlinear fashion[17]. Our own previous investigations also showed monometallic $\mathrm{Pd} / \mathrm{SiO}_{2}$ to be an effective catalyst for octanol Guerbet condensation but at the expense of selectivity. The replacement of Pd by Cu on the surface was found to address this issue by preventing the undesired decarbonylation reaction and shifting the selectivity towards $\mathrm{C}-\mathrm{H}$ bond activation $[18,19]$. Likewise, studies over PdCu catalysts have shown that adding the second metal comparatively improved the desired conversion pathway of furfural, a platform molecule derived from biomass $[10,20]$. Adding $\mathrm{Cu}$ to $\mathrm{Pd}$ was found to reduce the decarbonylation rate while increasing the formation of hydrogenation products such as furfuryl alcohol[20].

Missing however, is an understanding of how the electronic and chemical properties undergo modification relative to the parent metal in $\mathrm{PdCu}$ systems and how these properties affect the reactivity. Significant efforts in bimetallic alloy catalysis have revealed that there are two factors that impact the reactivity of a bimetallic catalytic system [21, 22]. The first is the formation of heterobonds that contributes to electronic changes in the catalytic system. The electronic structure is also modified by changes in geometry relative to the parent metal, such as a change in metal bond lengths, lattice distortion resulting in strain effects, or changes in coordination environment $[23,24]$. Second, ensemble effects, via the replacement of adjacent atoms, can greatly influence the types of surface intermediates and adsorbate adlayers that can stably form during the reaction [25].

To address this literature gap and to distinguish between electronic and structural effects, we undertake the present study. First, we investigate the role of the $\mathrm{Cu}: \mathrm{Pd}$ ratio in tuning the surface-adsorbate bonds while monitoring the synergistic effects. In the second avenue, we investigate the generality of electronic and structural effects in Pd-IB alloys, by replacing $\mathrm{Cu}$ with $\mathrm{Ag}$.

We achieve these two aims by measuring the rates of the competing hydrogenation and decarbonylation reactions of butyraldehyde over $\mathrm{Pd}_{x} \mathrm{Cu}_{y} / \mathrm{SiO}_{2}$ and $\mathrm{Pd}_{x} \mathrm{Ag}_{y} / \mathrm{SiO}_{2}$ catalysts. Characterization of the catalysts is achieved by TEM, X-Ray absorption and DFT calculations. The combination of kinetic measurements and characterization results show that the selectivity and reactivity changes upon the introduction of $\mathrm{Cu}$ into 
$\mathrm{Pd}$ is due to both ligand and ensemble effects. In contrast, in PdAg systems, the absence of selectivity shifts show that the reactivity is only influenced by the geometry, despite the electronic exchange between $\mathrm{Pd}$ and $\mathrm{Ag}$. Based on these investigations, we propose a novel catalytic system for the Guerbet condensation of ethanol comprised of a $\mathrm{PdCu}_{3} / \mathrm{SiO}_{2}$ catalyst in a mixture with $\mathrm{TiO}_{2}$.

\section{Materials and Methods}

Catalyst Synthesis. In this work, several PdCu alloys were prepared as supported nanoparticles through incipient wetness impregnation. These catalysts were supported on $\mathrm{SiO}_{2}$ (specific surface area of 0.75 $\mathrm{cm}^{3} / \mathrm{g}, 60-100$ mesh) obtained from Sigma-Aldrich. First, different concentrations of $\mathrm{Pd}\left(\mathrm{NO}_{3}\right)_{2}$ and $\mathrm{Cu}\left(\mathrm{NO}_{3}\right)_{2}$ were added to about $4 \mathrm{ml}$ of deionized water in a beaker and stirred until dissolved. Then this solution was deposited drop-by-drop on $5 \mathrm{~g}$ of $\mathrm{SiO}_{2}$ and mixed until combined. Finally, the solids were left to dry in air at ambient temperature for 16 hours, followed successively by calcination in air at $400{ }^{\circ} \mathrm{C}$ for 3 hours. The resulting catalyst is denoted as $\mathrm{Pd}_{x} \mathrm{Cu}_{y} / \mathrm{SiO}_{2}$, where $\mathrm{x}$ and $\mathrm{y}$ are the atomic compositions of the metal. $\mathrm{Pd}_{x} \mathrm{Ag}_{y} / \mathrm{SiO}_{2}$ catalysts are synthesized in a similar manner using $\mathrm{Pd}\left(\mathrm{NO}_{3}\right)_{2}$ and $\mathrm{AgNO}_{3}$ as precursors.

Titanium dioxide $\left(\mathrm{TiO}_{2}\right)$ was prepared via sol-gel hydrolysis precipitation. $29.6 \mathrm{~mL}$ of titanium isopropoxide (Sigma-Aldrich) were dissolved in $100 \mathrm{~mL}$ of ethanol (Fischer Scientific). This solution then was added dropwise into a mixture of $180 \mathrm{~mL}$ water and $100 \mathrm{~mL}$ ethanol at room temperature and stirring at $150 \mathrm{rpm}$ for 2 hours. The precipitates were collected by vacuum filtering the produced $\mathrm{TiO}_{2}$ mixture and dispersed in pure EtOH for 5 times. The obtained washed precipitates were dried in a fume hood under ambient conditions and went through the calcination process for 3 hours at $450^{\circ} \mathrm{C}$ to remove the volatile and organic species as well as acquire crystalline oxides of $\mathrm{TiO}_{2}$.

Catalyst Characterization. TEM images were taken on a TITAN STEM electron microscope at the Electron Microscopy facility of Oregon State University. The samples were supported on 200 mesh Au film grids purchased from Ted Pella, Inc. The grids were cleaned with a plasma etch treatment before samples were deposited onto them. The samples were ground with a mortar and pestle and then suspended in a mixture of ethanol and water. They were then sonicated for approximately five minutes before being deposited onto the plasma-treated sample grids and allowed to dry. The images were taken in TEM mode at $200 \mathrm{kV}$. The spot size was normally 3 and the magnification for the images was 150 to $300 \mathrm{kx}$. Representative electron micrographs and particle size distribution histograms for $\mathrm{Cu}, \mathrm{Pd}$ and their alloys are shown in the supporting information (Figure S1). The nanoparticle size increases with increasing $\mathrm{Cu}$ content in the catalyst, from an average of $3.8 \mathrm{~nm}$ in the monometallic Pd sample to $6.6 \mathrm{~nm}$ in the monometallic Cu sample.

$\mathrm{Pd}, \mathrm{Ag}$ and $\mathrm{Cu} \mathrm{K}$ edge $\mathrm{X}$-ray absorption measurements were made in the transmission mode on beamline 5BM-D of the Advanced Photon Source of Argonne National Laboratory. In these experiments, the catalysts were mixed with boron nitride (BN) and were pressed in self-supporting pellets and placed in a quartz tube situated in a clamshell furnace. The tube was enclosed by UltraTorr type fittings with welded ball valves and polyimide windows. Samples were treated in $10 \% \mathrm{H}_{2} / \mathrm{N}_{2}$ at $523 \mathrm{~K}$ prior to measurement and The $\mathrm{Pd}, \mathrm{Ag}$ and $\mathrm{Cu} \mathrm{K}$ edge spectra were collected using three ionization chambers which are used to measure the incident and transmission radiation through the sample and reference foil. The EXAFS oscillations for $\mathrm{Cu}$ ( $\mathrm{k}=2$ to 10 and $\mathrm{R}=1.8$ to 3.4 ), $\mathrm{Ag}$ and $\mathrm{Pd}(\mathrm{k}=2.5$ to 13.8 and $\mathrm{r}=1.8$ to 3.4) edges were fitted separately using Athena and Artemis of Demeter suite. 
$P d L_{I I I}$ edge absorption measurements were performed in fluorescence mode on beamline 9BM-B of the Advanced Photon Source of Argonne National Laboratory. In these experiments, the samples were mixed with $\mathrm{BN}$, pressed into pellets and placed into a cube reactor with polyimide windows. Gas flows (He, H2, $10 \% \mathrm{O}_{2} / \mathrm{He}$ and $20 \% \mathrm{CO} / \mathrm{He}$ ) were metered by electronic mass flow controllers. The Pd LIII XANES spectra were recorded using a Hitachi Vortex ME4 detector. The energy scales of the spectra were calibrated on the point of inflation for the $\mathrm{Pd} \mathrm{L}_{\| 1}$ edge at $3174.6 \mathrm{eV}$ for a PdO sample. In a typical experiment, catalysts were reduced in a $100 \mathrm{ml} / \mathrm{min} 10 \% \mathrm{H}_{2} / \mathrm{He}$ mixture at $250{ }^{\circ} \mathrm{C}$ for $45 \mathrm{~min}$ (ramp equal to $5{ }^{\circ} \mathrm{C} / \mathrm{min}$ ) and cooled down under the same flow to $150^{\circ} \mathrm{C}$ and scanned. The flow was then changed to He, to measure under inert conditions, followed by measurements under $20 \% \mathrm{CO} / \mathrm{He}(100 \mathrm{ml} / \mathrm{min})$.

Catalytic Performance Evaluation. The reactions of butyraldehyde (Tokyo Chemical Industry - used without further purification) over $\mathrm{Pd}_{x} \mathrm{Cu}_{\mathrm{y}} / \mathrm{SiO}_{2}$ catalysts were evaluated in a gas phase flow reactor. Electronic mass flow controllers (Brooks 5850) were used to control all gas flows. Gases were 99.99\% or more pure and were obtained from Airgas. The liquid reactant was introduced using a $2.5 \mathrm{~mL}$ Hamilton syringe. The flow of the liquid reactant was controlled by a Harvard apparatus syringe pump with typical flow rates between 0.05 to $0.1 \mathrm{~mL} / \mathrm{min}$. In a typical experiment, around $25 \mathrm{mg}$ of catalyst diluted with silica is loaded into a flow-through sample tube. The reactor set-up is enclosed in a ceramic clam-shell furnace. The temperature inside the furnace is measured by a $\mathrm{K}$ type thermocouple and controlled by a PID controller. Before the catalytic tests, the catalyst was pretreated with flowing $10 \% \mathrm{H}_{2} / \mathrm{Ar}\left(20 \mathrm{~mL} \mathrm{~min}^{-1}\right)$ at $250{ }^{\circ} \mathrm{C}$ for $45 \mathrm{~min}$ (ramp rate $5^{\circ} \mathrm{C} / \mathrm{min}$ ). Following that, the sample was cooled to $150{ }^{\circ} \mathrm{C}$. Experiments were conducted under flowing $10 \% \mathrm{H}_{2} / \mathrm{Ar}$ at $150{ }^{\circ} \mathrm{C}$, with gas flow rates ranging from $20-60 \mathrm{~mL} / \mathrm{min}$. The products from the reactor outlet were analyzed by on-line gas chromatography (Shimadzu, GC 2014) equipped with TCD and FID analysis channels. These were connected to a HayeSep D $6 \mathrm{ft}, 1 / 8$ in OD packed column and an HP-1 60 m capillary column. Rates reported herein correspond to $10 \%$ conversion and turnover frequencies are normalized by the dispersion as calculated by assuming cubo-octahedral particles of an average diameter equal to the surface average diameter, as determined by the TEM.

Ethanol Guerbet reactions were performed in a gas-phase reactor similar to the one described above. All experiments were conducted at $250{ }^{\circ} \mathrm{C}$, in a flow of hydrogen $(90 \mathrm{kPa})$ and ethanol $(11 \mathrm{kPa})$. Prior to reaction, the catalyst, comprised of a physical mixture of $\mathrm{Pd}_{\mathrm{x}} \mathrm{Cu}_{\mathrm{y}} / \mathrm{SiO}_{2}$ and $\mathrm{TiO}_{2}$ (4:1 by mass) was purged with $\mathrm{H}_{2}$ at $250{ }^{\circ} \mathrm{C}$ for $30 \mathrm{~min}$. The space velocity was varied to achieve a conversion between $8 \%$ and $12 \%$. Analysis of the products was conducted by online GC as described above. Results reported herein correspond to data after $7 \mathrm{~h}$ on-stream. Rates are given on a per-gram-of-total-catalyst basis, to reflect the bifunctionality of the catalyst, wherein dehydrogenation takes place over the metallic catalyst and aldol condensation over the $\mathrm{TiO}_{2}$.

Computational method. Periodic, spin-paired density functional theory (DFT) calculations were performed using the Vienna ab initio Simulation Package (VASP) [26-28],combined with the Atomic Simulation Environment (ASE)[29]. The interactions between the ionic cores and valence electrons were described using projector augmented wave (PAW) potentials [30, 31]. The Perdew-Wang exchange and correlation functional (PW 91) was applied with an energy cutoff of $400 \mathrm{eV}$ [32]. 
Table 1: Lattice constants of bulk metals and alloys

\begin{tabular}{|c|c|c|c|c|c|c|c|}
\hline Bulk structure & $\mathrm{Cu}$ & $\mathrm{Cu}_{3} \mathrm{Pd}$ & $\mathrm{CuPd}_{3}$ & $\mathrm{Pd}$ & $\mathrm{AgPd}_{3}$ & $\mathrm{Ag}_{3} \mathrm{Pd}$ & $\mathrm{Ag}$ \\
\hline $\begin{array}{c}\text { Lattice constant }(\AA) \\
\begin{array}{c}\text { Average interatomic } \\
\text { distance }(\AA)\end{array}\end{array}$ & 3.661 & 3.729 & 3.889 & 3.891 & 4.007 & 4.103 & 4.156 \\
\hline
\end{tabular}
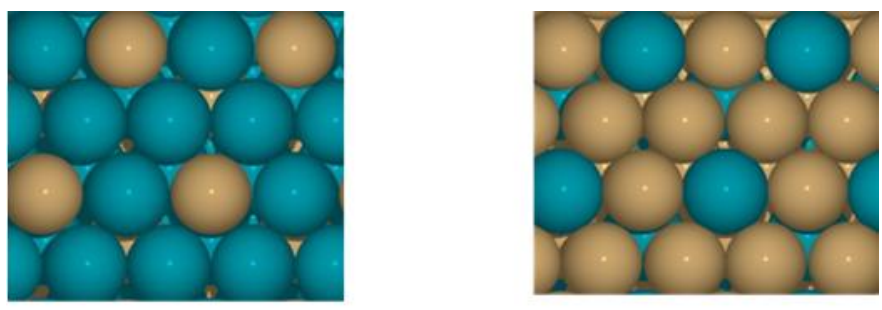

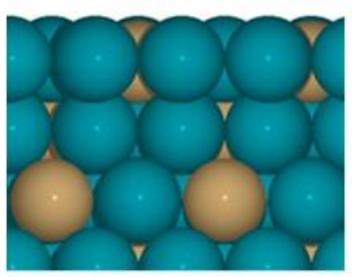

(a)

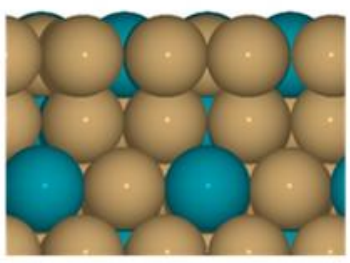

(b)

Figure 1: (a) top (top) and side (bottom) view of the $\mathrm{CuPd}_{3}(111)$ surface (b) top (top) and side (bottom) view of the $\mathrm{Cu}_{3} P d(111)$ surface

We modeled the (111) surfaces of $L 1_{2}$ type alloys as four-layer slabs, with the top two layers fully relaxed and the bottom two layers fixed to the bulk truncated positions. The optimized bulk lattice constants are listed below in Table 1. For all surfaces we used a $4 \times 4$ unit cell, and a $20 \AA$ vacuum space was applied in the $z$ direction between any repeated slabs. Figure 1 shows a snapshot of the PdCu alloy surfaces; AgPd surfaces follow the same arrangement. A Monkhorst-Pack k-point mesh of $(4 \times 4 \times 1)$ was used to sample the Brillouin zone[33]. Gaussian smearing with a Fermi temperature of $k_{b} T=0.1 \mathrm{eV}$ was employed, and the total energy was extrapolated to $k_{b} T=0.0 \mathrm{eV}[34,35]$. A dipole correction was applied in the direction normal to the surface[36]. Geometries were considered converged when the force was below $0.02 \mathrm{eV} / \AA$.

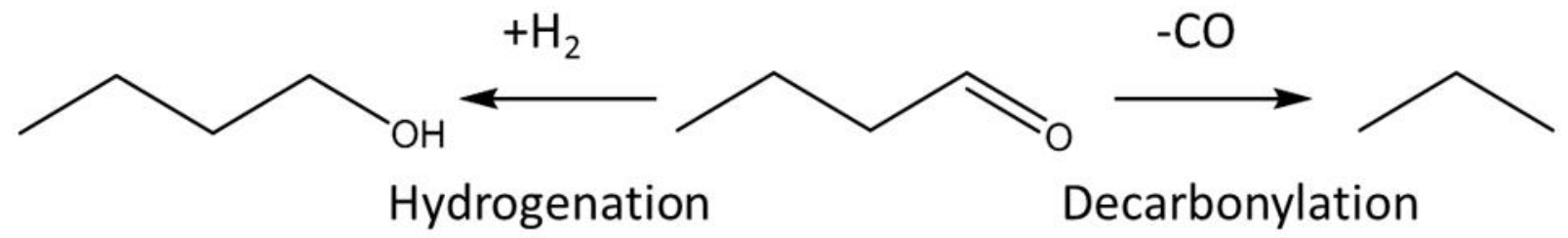

Scheme 1: Competing reactions Selective hydrogenation and Unselective decarbonylation routes of butyraldehyde 


\section{Results and discussion}

As a first step, we probe the competing butyraldehyde reactions to evaluate the potential utility of these catalysts in an industrially practical reaction. We showed in previous work that the butyraldehyde hydrogenation and decarbonylation reactions were a good proxy for the industrially-relevant $A B E$ condensation reaction [19, 37]. Based on this, we posit that the selectivity trend of the butyraldehyde hydrogenation will parallel that of the selectivity of the industrially-relevant Guerbet reaction (Scheme 2). The Guerbet reaction of alcohols requires the dehydrogenation of the alcohol to the reactive aldehyde $[38,39]$, a reaction that can be viewed as the microscopic reverse of the hydrogenation of an aldehyde to an alcohol. Moreover, one of the main pathways to selectivity losses during the Guerbet reaction is the CC bond cleavage of acetaldehyde via decarbonylation [40].

The rate of decarbonylation and hydrogenation of butyraldehyde (Scheme 1) over a range of monometallic and bimetallic catalysts was measured as a function of the space velocity. Lower space velocity leads to increasing conversion and a decrease of turnover rates, for both decarbonylation and hydrogenation reactions (Representative data shown in Figure 2). This is attributed to the production of $\mathrm{CO}$ during reaction and the poisoning of surface sites due to its strong adsorption to the surface [19].
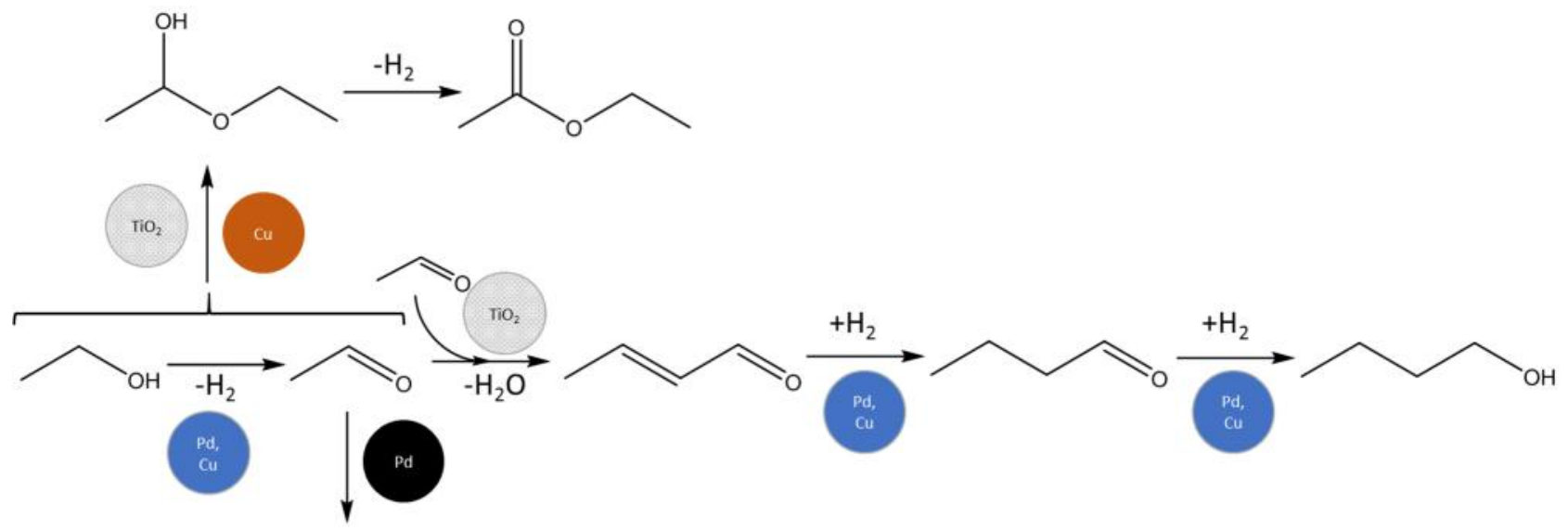

$\mathrm{CH}_{4}$

Scheme 2: Guerbet reaction of ethanol over mixtures of metal and oxide catalysts.

Comparison of monometallic and bimetallic Pd-based catalysts showed that adding $\mathrm{Cu}$ to $\mathrm{Pd}$ significantly altered the product distribution, shifting selectivity to the hydrogenation reaction. Monometallic $\mathrm{Pd}$ shows a selectivity to hydrogenation lower than 20\%; upon addition of $\mathrm{Cu}$, selectivity shifts to the hydrogenation product, reaching $100 \%$ over a monometallic $\mathrm{Cu}$ catalyst. This is consistent with our previous results $[41,42]$, and suggests that $\mathrm{Pd}-\mathrm{Pd}$ ensembles responsible for decarbonylation are disrupted by the presence of copper on the surface. 


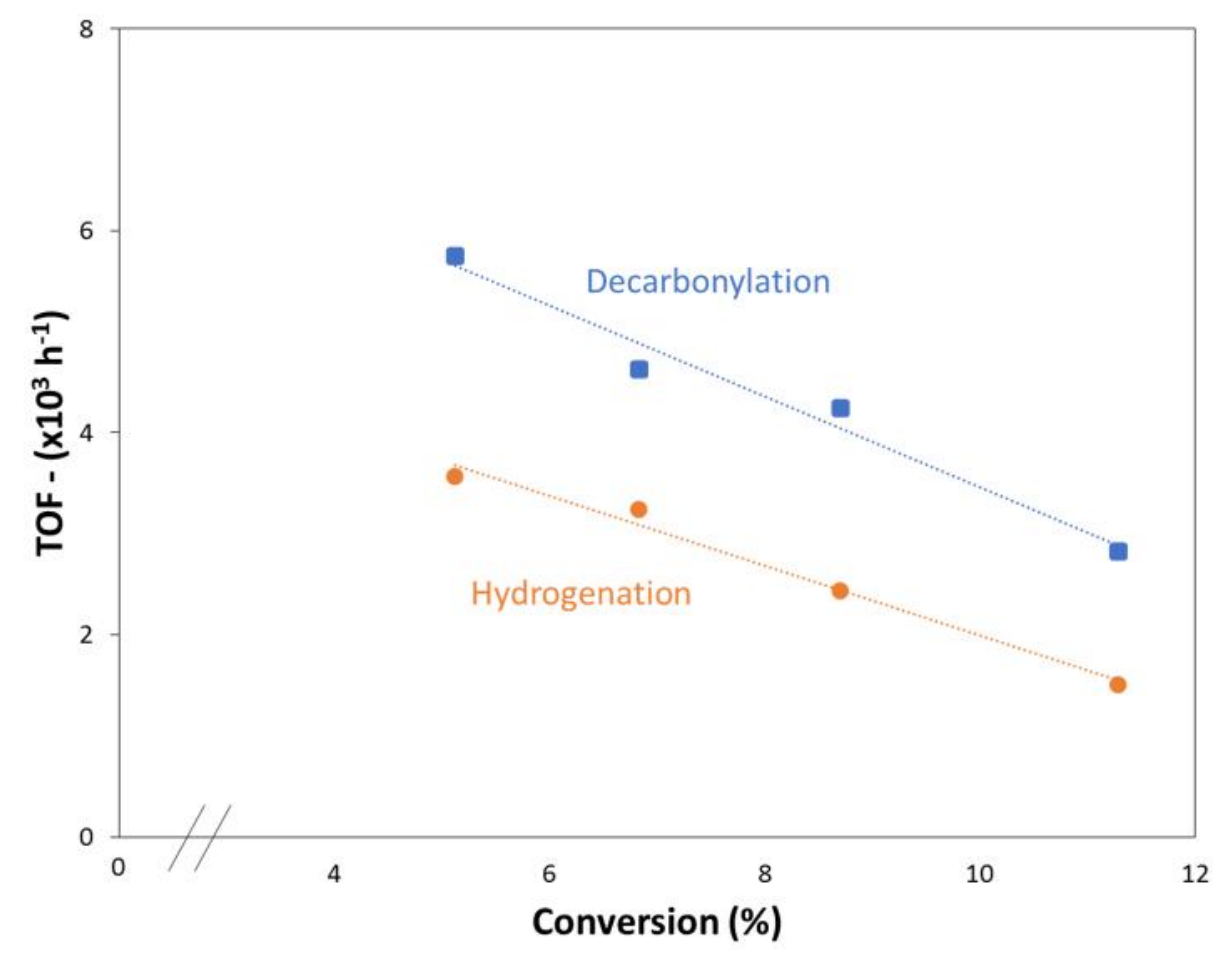

Figure 2: Decarbonylation and hydrogenation turnover frequency as function of conversion over $\mathrm{Pd}_{1} \mathrm{Cu}_{1} / \mathrm{SiO}_{2}$ at $423 \mathrm{~K}, 4 \mathrm{kPa}$ butyraldehyde, $10 \mathrm{kPa} \mathrm{H}_{2}$, and balance $\mathrm{N}_{2}$.

The presence of $\mathrm{Cu}$ in the surface is attested in the XAS results, which show a lower total coordination number on the $\mathrm{Cu}$ edge, compared to the $\mathrm{Pd}$ edge for the $\mathrm{Pd}_{3} \mathrm{Cu}$ and $\mathrm{Pd}_{1} \mathrm{Cu}_{1}$ samples. This result is in seeming contrast with the recent results of Ball et al. [43], which show Pd preferentially segregated to the surface; we believe that this difference can be explained by the different particle size of the two catalysts. In the work of Ball et al. [43], the catalyst particles are much smaller ( $2 \mathrm{~nm}$ ) than ours; we have shown in our previous work [19] that higher index planes, such as those found in smaller nanoparticles tend to stabilize surface $\mathrm{Pd}$ atoms, as opposed to surface $\mathrm{Cu}$ atoms. This may account for the observed difference in surface segregation.

Table 2 shows that as the $\mathrm{Cu}$ fraction increases from $\mathrm{Pd}_{3} \mathrm{Cu}$ to $\mathrm{Pd}_{1} \mathrm{Cu}$, the average $\mathrm{Pd}$ atom is surrounded by more $\mathrm{Cu}$ atoms. This way, more $\mathrm{Pd}-\mathrm{Pd}$ ensembles are disrupted by the presence of $\mathrm{Cu}$ until we see no evidence for Pd-Pd pairs in the $\mathrm{PdCu}_{3}$ sample. The disruption of the Pd-Pd ensembles is manifested in the selectivity patterns shown in Figure 3. Decarbonylation selectivity is reduced, as the Pd-Pd active sites are removed. 
Table 2: EXAFS fits for PdCu catalysts after reduction at $523 \mathrm{~K}$ in a 10\% $\mathrm{H} 2 / \mathrm{He}$ flow. Spectra recorded under He flow. Data and fit plots are shown in Supporting Information Figures S2-S7.

\begin{tabular}{ccccccc}
$\begin{array}{c}\text { Sample } \\
\text { name }\end{array}$ & Edge & $\begin{array}{c}\text { Near-neighbor } \\
\text { species }\end{array}$ & $\begin{array}{c}\mathbf{N} \\
\text { (co-ordination } \\
\text { number) }\end{array}$ & $\mathrm{E}_{\mathrm{o}}(\mathrm{eV})$ & $\mathbf{\sigma}^{2}\left(\mathbf{1 0}^{4} \AA^{-2}\right)$ & $\mathbf{r}(\AA)$ \\
\hline $\mathrm{Pd}_{3} \mathrm{Cu}_{1}$ & $\mathrm{Pd}$ & $\mathrm{Pd}$ & $8.4 \pm 0.6$ & & \\
& & $\mathrm{Cu}$ & $4.2 \pm 0.7$ & $-4.7 \pm 0.5$ & $128 \pm 10$ & $2.636 \pm 0.012$ \\
\cline { 2 - 7 } & $\mathrm{Cu}$ & $\mathrm{Pd}$ & $5.8 \pm 1.0$ & $0.4 \pm 0.9$ & $128 \pm 10$ & $2.636 \pm 0.012$ \\
& & $\mathrm{Cu}$ & $5.4 \pm 1.3$ & & $128 \pm 10$ & $2.771 \pm 0.010$ \\
\hline $\mathrm{Pd}_{1} \mathrm{Cu}_{1}$ & $\mathrm{Pd}$ & $\mathrm{Pd}$ & $5.8 \pm 2.0$ & & $110 \pm 41$ & $2.671 \pm 0.021$ \\
& & $\mathrm{Cu}$ & $6.5 \pm 1.5$ & $-6.9 \pm 1.8$ & $117 \pm 15$ & $2.582 \pm 0.008$ \\
\cline { 2 - 7 } & $\mathrm{Cu}$ & $\mathrm{Pd}$ & $5.3 \pm 0.5$ & $-0.2 \pm 0.5$ & $117 \pm 15$ & $2.582 \pm 0.008$ \\
& & $\mathrm{Cu}$ & $2.4 \pm 0.3$ & & $117 \pm 15$ & $2.531 \pm 0.013$ \\
\hline $\mathrm{Pd}_{1} \mathrm{Cu}_{3}$ & $\mathrm{Pd}$ & $\mathrm{Pd}$ & - & & - & - \\
& & $\mathrm{Cu}$ & $8.2 \pm 2.3$ & & $101 \pm 25$ & $2.551 \pm 0.017$ \\
\cline { 2 - 7 } & $\mathrm{Cu}$ & $\mathrm{Pd}$ & $2.1 \pm 0.4$ & $1.4 \pm 0.8$ & $101 \pm 25$ & $2.551 \pm 0.017$ \\
& & $\mathrm{Cu}$ & $4.4 \pm 0.5$ & & $101 \pm 25$ & $2.551 \pm 0.009$ \\
\hline
\end{tabular}

The $\mathrm{PdCu}_{3}$ sample shows only $\mathrm{Pd}-\mathrm{Cu}$ scattering on the $\mathrm{Pd}$ edge, suggesting that $\mathrm{Pd}$ atoms are completely isolated in the $\mathrm{Cu}$. This isolation of $\mathrm{Pd}$ atoms is responsible for the almost-complete suppression of decarbonylation over the $\mathrm{PdCu}_{3}$ sample. We observe that the selectivity patterns over a $\mathrm{Cu}: \mathrm{Pd} \mathrm{3:1} \mathrm{alloy}$ are similar to those of the pure $\mathrm{Cu}$ catalyst. Moreover, we note that the turnover frequency for hydrogenation is significantly higher than that over the $\mathrm{Cu}$ catalyst. Taken together, these two observations suggest that the alloying of $\mathrm{Pd}$ and $\mathrm{Cu}$ results in the formation of a surface with a new active site: $\mathrm{Cu}$ centers promoted by $\mathrm{Pd}$. This surface is unable to simultaneously stabilize alkyl fragments and $\mathrm{CO}$ due to the isolation of $\mathrm{Pd}$, while the $\mathrm{Cu}$ centers show distinct activity compared to pure $\mathrm{Cu}$. More specifically, the increased turnover frequency of the $\mathrm{Cu}_{3} \mathrm{Pd}$ catalyst compared to $\mathrm{Cu}$ suggests a promotional effect of $\mathrm{Pd}$ on $\mathrm{Cu}$. We attribute this promotional effect to electron exchange between $\mathrm{Cu}$ and $\mathrm{Pd}$. We posit that alloying induces shifts in the $\mathrm{d}$-bands of $\mathrm{Cu}$ and $\mathrm{Pd}$ and electron density transfer from $\mathrm{Cu}$ to $\mathrm{Pd}$, hence promoting the $\mathrm{Cu}$ and increasing the reaction rate for hydrogenation. 


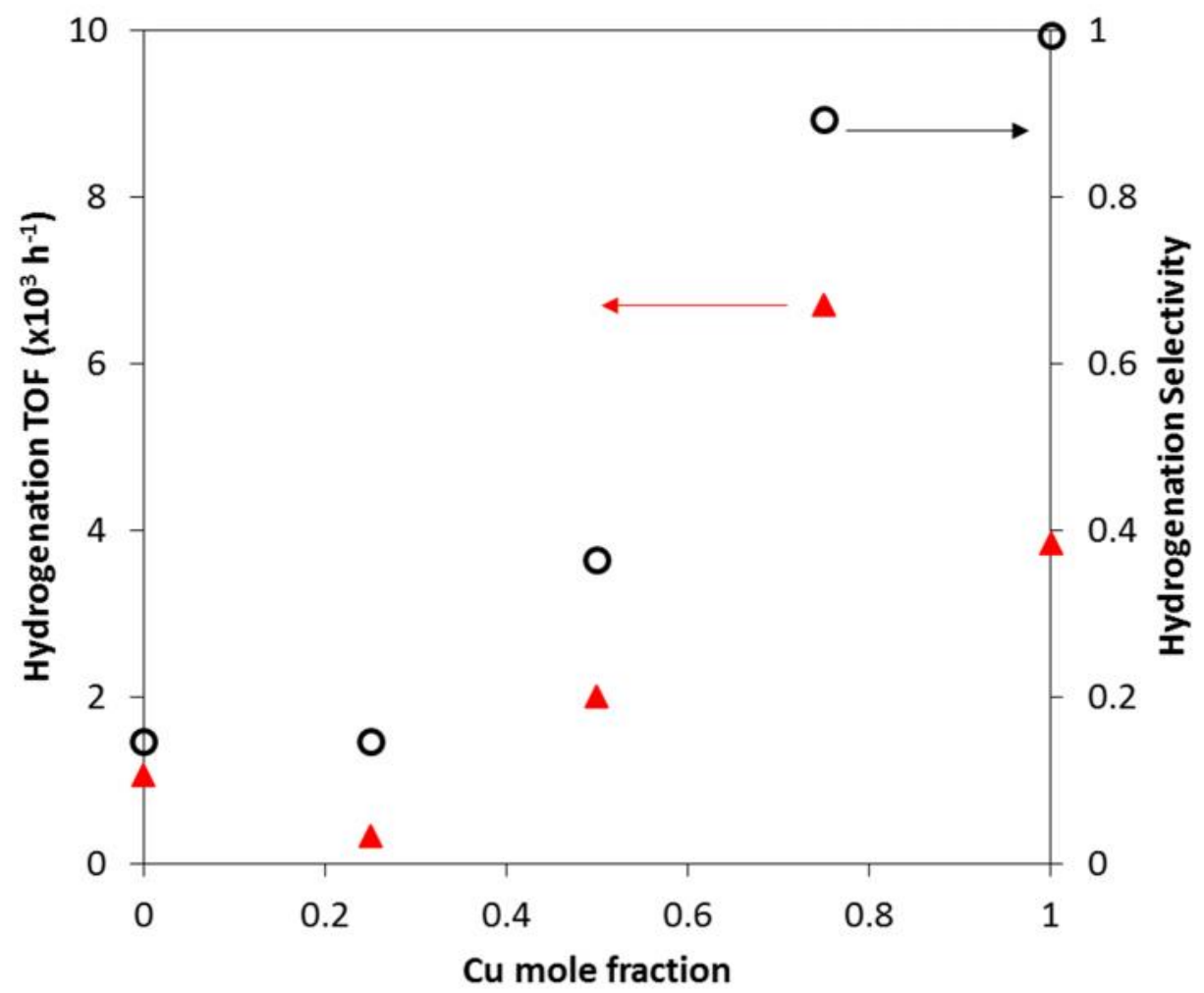

Figure 3: Effects of Cu mole fraction on the hydrogenation rate and selectivity of Pd-Cu catalysts. $423 \mathrm{~K}, 4 \mathrm{kPa}$ butyraldehyde, 10 $\mathrm{kPa} \mathrm{H}$, balance $\mathrm{N}_{2}$. TOF values intrapolated to $10 \%$ conversion.

To probe this hypothesis, we carried out Pd $\mathrm{L}_{\text {III }}$ XANES experiments and DFT calculations. In Pd $\mathrm{L}_{\text {III }}$ edge XANES, $2 p 3 / 2$ electrons are excited. This enables probing of the $P d 4 d$ band, as the $2 p 3 / 2 \rightarrow 4 d$ transition is symmetry-allowed. Furthermore, the $L_{I I I}$ XANES conducted under different reaction conditions elucidates the density of states (DOS) of empty d-orbitals that probes possible charge transfer between alloyed metal atoms $[44,45]$. Several theoretical studies have confirmed the relationship between white line intensity and the DOS of d-orbitals [44-47]. The center of the $d$-band is governed by the d-bandwidth, and the number of unoccupied d-band orbitals which is a function of the spatial extent of $d$-orbitals [47].

As the $\mathrm{Cu}$ content in the catalyst increases, there is a shift of the edge position to higher energies and an increase of the area of a feature centered around $3182 \mathrm{eV}$. Furthermore, the edge energy increases by $0.7 \mathrm{eV}$ from a pure $\mathrm{Pd}$ to a $\mathrm{Cu}_{3} \mathrm{Pd}$ catalyst. The edge shift to higher energies shows a partial reduction (electron gain) of the $\mathrm{Pd}$ atoms, which is consistent with the picture outlined by the electronic model obtained from DFT. In this model, the d-band of Pd changes to energies further from the Fermi level (Figure 5), from $-1.43 \mathrm{eV}$, for pure $\mathrm{Pd}(111)$, to $-1.76 \mathrm{eV}$ in the $\mathrm{Cu}_{3} \mathrm{Pd}(111)$ surface. Concurrent with this shift on the Pd electronic structure, there is negative charging of the Pd atoms in the PdCu alloy, as evidenced by the Bader charge calculations (Figure S12), and consistent with the observed XANES edge 
shift.
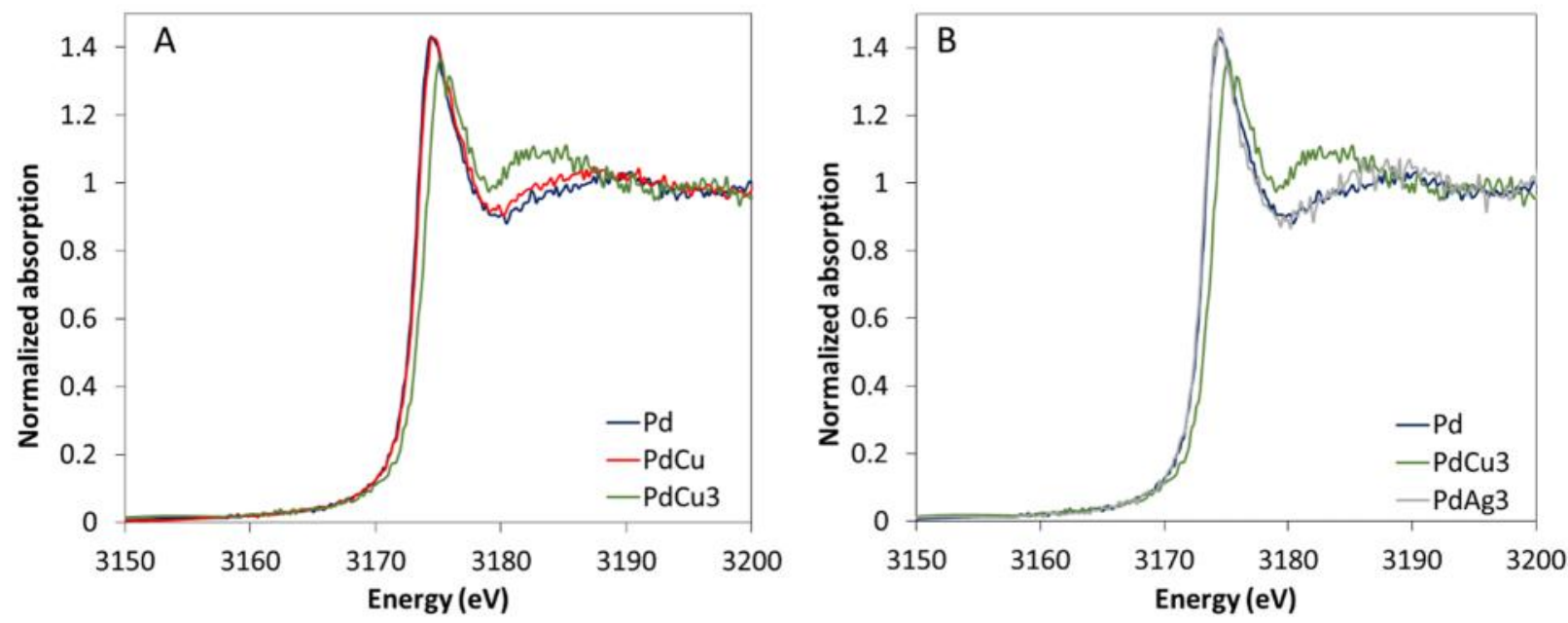

Figure 4: Pd LIII edge XANES of PdCu ( $\mathrm{A}$ and B) and PdAg (B) catalysts. Spectra were recorded after reduction of the catalysts at $523 \mathrm{~K}$. Spectra recorded at $423 \mathrm{~K}$ under He flow.

Furthermore, the increase of the XANES feature at $3182 \mathrm{eV}$ is consistent with the formation of new antibonding electronic states. This is a manifestation of hybridization of $\mathrm{Pd} d$-states due to interaction with the valence bonds of alloying Cu metal. Moreover, the observed reduction in the white line intensity as the $\mathrm{Cu}$ fraction increases from 0 to 0.75 is attributed to the shift in electron density from $\mathrm{Cu}$ to $\mathrm{Pd}$ [24, $29,30]$. In contrast, $\mathrm{Cu}$ atoms gain activity upon alloying, as evidenced by their large $d$-band center shift closer to the Fermi level. As shown in Figure 5, the $d$-band center of pure $\mathrm{Cu}$ is at $-2.23 \mathrm{eV}$, but $-1.50 \mathrm{eV}$ for $\mathrm{CuPd}_{3}$. Notably, the $\mathrm{Cu} d$-band center in $\mathrm{CuPd}_{3}$ is nearly identical to that of pure $\mathrm{Pd}(-1.43 \mathrm{eV})$ suggesting that the electronic structure of alloyed $\mathrm{Cu}$ atoms is a strong function of their local environment.

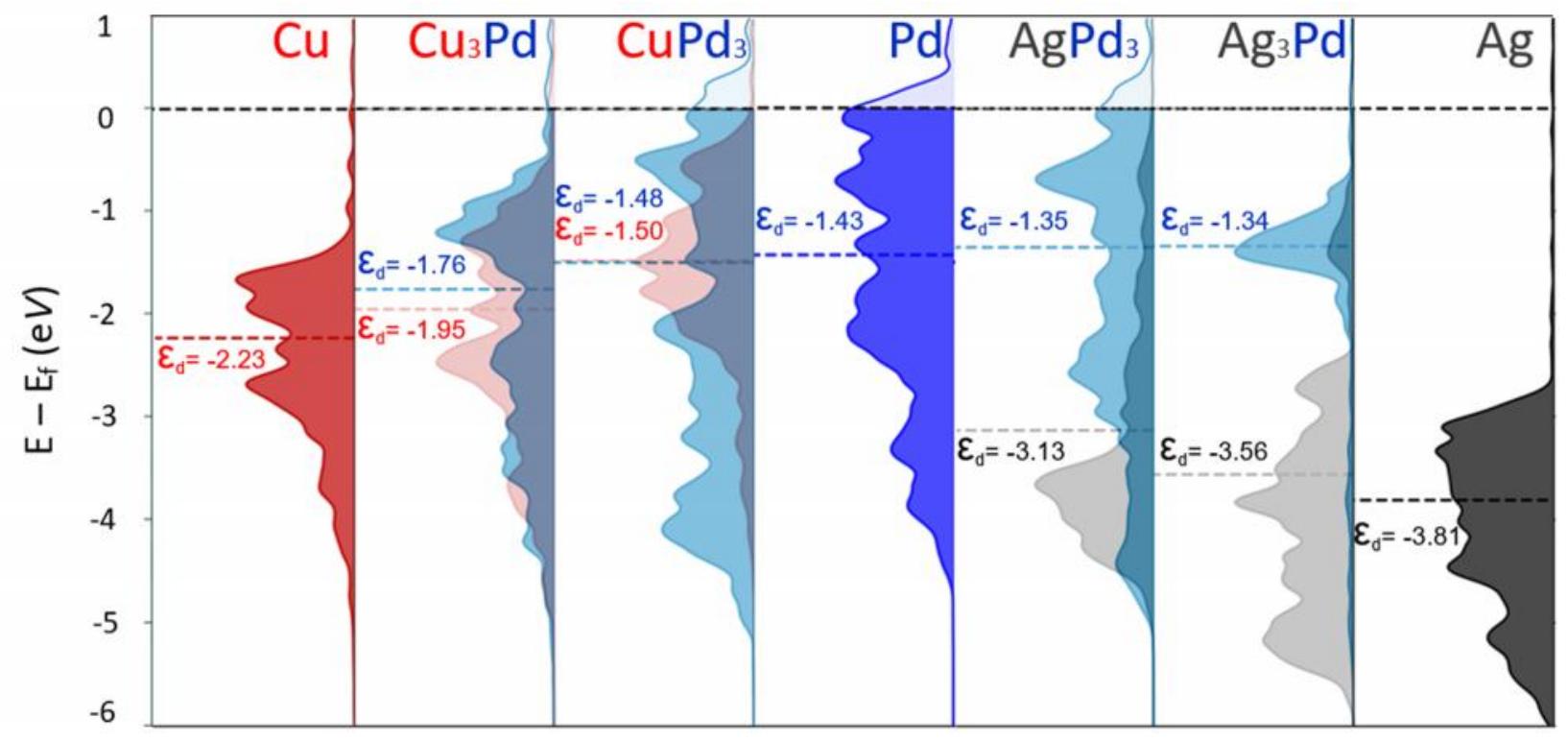

Figure 5: Density of states and d-band centers on the $f c c(111)$ surface of $\mathrm{Cu}, \mathrm{Pd}, \mathrm{Ag}$, and their alloys. 
Experiments in $\mathrm{H}_{2}$ and $\mathrm{CO}$ atmospheres were also performed (Figures $\mathrm{S} 11$ and $\mathrm{S} 12$ ). During the $\mathrm{H}_{2}$ flow experiments, the presence of Cu results in the disappearance of features associated with surface hydride formation[48]. This way, the spectra are indistinguishable from those acquired under He for the same catalysts. Spectra under $\mathrm{CO}$ show strong perturbations: broadening of the white lines and a shift of the edge to higher energy[49]. The strongest perturbation is shown by the Pd sample and the effects of CO adsorption on the Pd edge diminish with increasing $\mathrm{Cu}$ content. Both observations are consistent with $\mathrm{Cu}-$ rich surfaces on the alloy nanoparticles.

Based on Mendeleev's principles, $\mathrm{Cu}$ and $\mathrm{Ag}$ should behave similarly, given their position in the periodic table. Therefore, our hypothesis is that $\mathrm{PdCu}$ and $\mathrm{PdAg}$ alloys should show similar trends in the decarbonylation and hydrogenation reactions. To probe this hypothesis, we conducted similar space velocity and XAS experiments, as reported above for the PdCu samples.

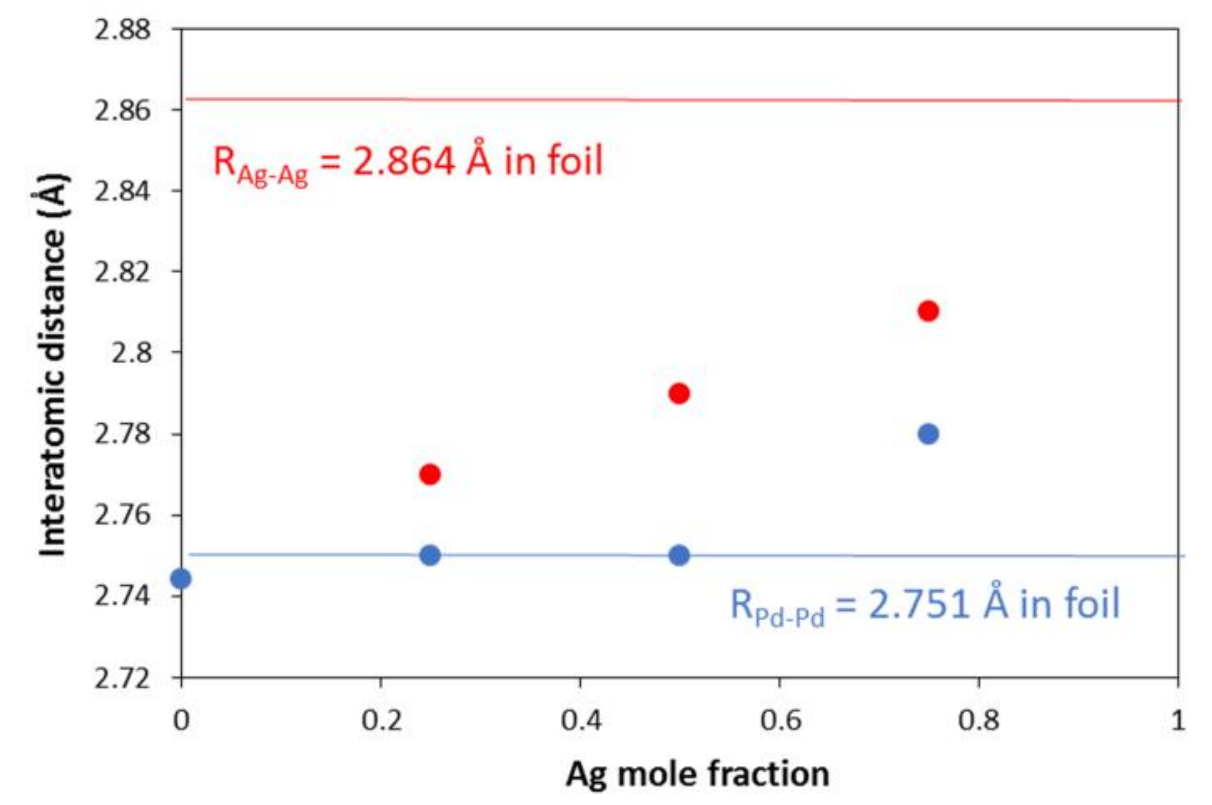

Figure 6: Interatomic distance of Pd-M (blue) and Ag-M (red) in PdAg alloy catalyst samples.

Similar to the PdCu alloy samples, alloying of Pd and $\mathrm{Ag}$ is observed, with an Ag-rich surface. As seen in Figure 6, the Pd-M distance is longer than the Pd-Pd distance in pure $\mathrm{Pd}$ and the $\mathrm{Ag}-\mathrm{M}$ distance is shorter than the $\mathrm{Ag}-\mathrm{Ag}$ distance in a pure $\mathrm{Ag}$ sample, indicating that alloying of $\mathrm{Pd}$ and $\mathrm{Ag}$ takes place. This observation is consistent with the calculated bulk lattice constants and average interatomic distances in Table 1, which are monotonically increasing from Pd to Ag. Furthermore, the fact that the Ag-M coordination number reported from EXAFS fits in Table 3 is consistently lower than the Pd-M coordination number strongly suggests enrichment of the surface in Ag. 
Table 3: EXAFS fit results for PdAg catalysts. Note that Pd and Ag scattering paths are not separated due to the similarity of the scattering parameters between the two atoms. Data and fit plots are shown in Supporting Information Figures S8-S9.

\begin{tabular}{ccccccc}
$\begin{array}{c}\text { Sample } \\
\text { name }\end{array}$ & Edge & $\begin{array}{c}\text { Near-neighbor } \\
\text { species }\end{array}$ & $\begin{array}{c}\mathbf{N} \\
\text { (co-ordination } \\
\text { number) }\end{array}$ & $E_{\mathrm{o}}(\mathbf{e V})$ & $\mathbf{\sigma}^{2}\left(10^{4} \AA^{-2}\right)$ & $\mathbf{r}(\AA)$ \\
\hline $\mathrm{Pd}_{3} \mathrm{Ag}_{1}$ & $\mathrm{Pd}$ & $\mathrm{M}$ & $10.3 \pm 0.5$ & $-8.8 \pm 0.3$ & $97 \pm 4.0$ & $2.750 \pm 0.003$ \\
\cline { 2 - 7 } & $\mathrm{Ag}$ & $\mathrm{M}$ & $9.9 \pm 0.9$ & $-4.3 \pm 0.5$ & $120 \pm 14$ & $2.771 \pm 0.010$ \\
\hline $\mathrm{Pd}_{1} \mathrm{Ag}_{1}$ & $\mathrm{Pd}$ & $\mathrm{M}$ & $11.1 \pm 0.6$ & $-5.0 \pm 0.4$ & $110 \pm 5.0$ & $2.753 \pm 0.004$ \\
\cline { 2 - 7 } & $\mathrm{Ag}$ & $\mathrm{M}$ & $8.0 \pm 1.3$ & $2.3 \pm 0.9$ & $155 \pm 27$ & $2.794 \pm 0.020$ \\
\hline $\mathrm{Pd}_{1} \mathrm{Ag}_{3}$ & $\mathrm{Pd}$ & $\mathrm{M}$ & $11.6 \pm 0.5$ & $-4.8 \pm 0.3$ & $105 \pm 4.0$ & $2.779 \pm 0.003$ \\
\cline { 2 - 7 } & $\mathrm{Ag}$ & $\mathrm{M}$ & $10.2 \pm 1.4$ & $-2.0 \pm 0.8$ & $175 \pm 23$ & $2.811 \pm 0.014$
\end{tabular}

Contrary to what was observed in the $\mathrm{PdCu}$ experiments, the reaction rates for hydrogenation and decarbonylation decrease simultaneously with increasing Ag content, resulting in minimal changes in selectivity upon introduction of $\mathrm{Ag}$ into $\mathrm{Pd}$ catalysts (Figure 7). This observation suggests that $\mathrm{Pd}$ provides the surface active site for both reactions and their number decreases by the addition of Ag. Moreover, Ag does not promote the active $\mathrm{Pd}$ sites by alloying. This picture is consistent with the $\mathrm{L}_{\text {III }}$ edge XANES results: minimal changes are observed in the Pd spectra between a Pd sample and a $\mathrm{PdAg}_{3}$ sample.

Our DFT calculations are consistent with the XAS results shown in Figure 4B. We observe minimal changes in the $\mathrm{Pd} d$-band center as a result of alloying $\mathrm{Pd}$ and $\mathrm{Ag}$ and the charge transfer from $\mathrm{Ag}$ to $\mathrm{Pd}$ as quantified by Bader charges in Figure $\mathrm{S} 12$ is less pronounced than in the case of $\mathrm{Cu}$. In the CuPd system we attributed the activity and selectivity improvements to electronically promoted surface $\mathrm{Cu}$ atoms as a result of alloying with Pd. While the $\mathrm{Ag} \mathrm{d}$-band center is also shifted upwards by $0.68 \mathrm{eV}$ and $0.25 \mathrm{eV} \mathrm{in} \mathrm{AgPd}_{3}$ and $\mathrm{Ag}_{3} \mathrm{Pd}$, respectively (Figure 5), it remains far away from the Fermi level (Figure 5). Even in the Pd-rich $\mathrm{AgPd}_{3}$ alloy the $d$-band center only reaches $-3.13 \mathrm{eV}$, which is much lower than that of pure $\mathrm{Cu}\left(\varepsilon_{d}=-2.23 e\right)$. Despite the electronic promotion of Ag with Pd (evidenced by the Pd L ${ }_{\| 1}$ XANES in Figure 4B, $d$-band centers in Figure 5 and the Bader charge calculations in Figure S12) the activity of Ag remains undetectable and only the geometric effect, i.e., the loss of active $\mathrm{Pd}$ sites, is reflected in the measured catalytic performance shown in Figure 7.

The reason for the investigation of the butyraldehyde reactions is to predict the intrinsic ability of the $\mathrm{PdCu}, \mathrm{PdAg}$ and Pd materials to selectively catalyze the ethanol Guerbet reaction (Scheme 2). We posit that catalysts that show high rates and selectivity in the butyraldehyde hydrogenation reactions will also show high rates and selectivity for the upgrading of ethanol to butanol and higher oxygenates; we have shown the efficacy of this approach in screening similar ABE condensation catalysts[19] . This assumption is based on the hydrogenation of aldehydes being the microscopic reverse of the dehydrogenation of alcohols, the rate-determining step of the Guerbet condensation $[13,50]$. 


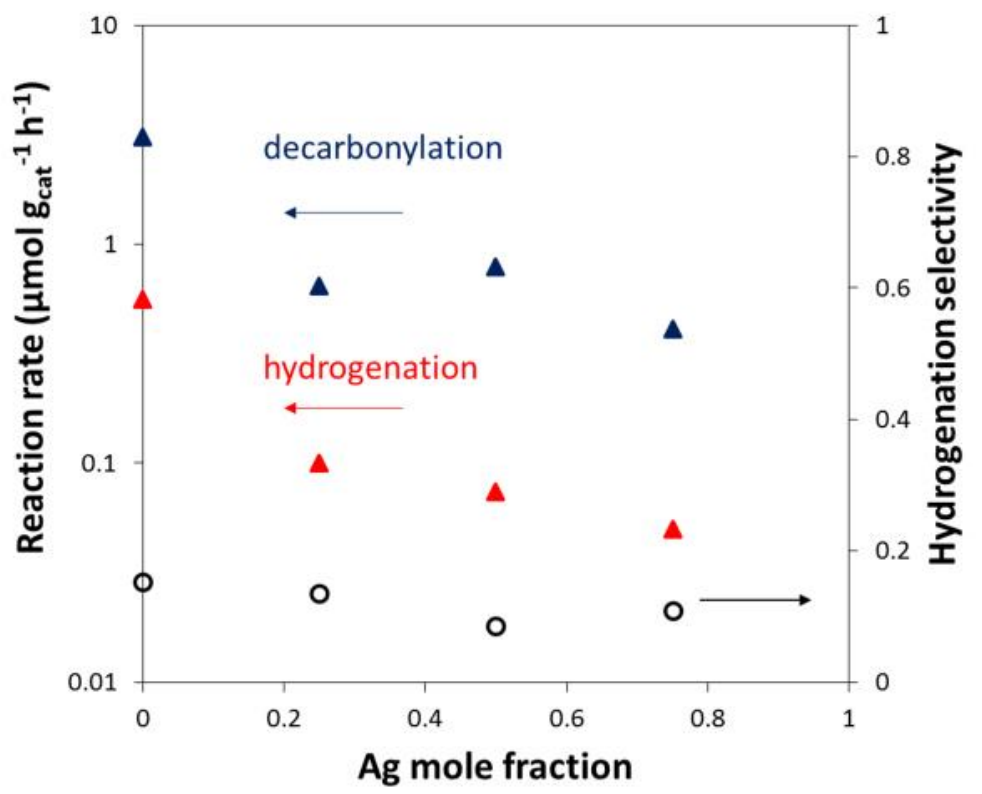

Figure 7: Effects of Ag mole fraction on the decarbonylation and hydrogenation rates and selectivity.

In our experiments, the $\mathrm{PdCu}$ alloys acted as ethanol dehydrogenation catalysts, while $\mathrm{TiO}_{2}$ was used as a co-catalyst $[9,19,51]$. The role of $\mathrm{TiO}_{2}$ is to catalyze the formation of the $\mathrm{C}$ - $\mathrm{C}$ bond between aldehydes in an aldol condensation reaction, as shown in Scheme 2 [13]. The results of our experiments are shown in Figure 8 , juxtaposed with the butyraldehyde hydrogenation results. Just as the highest rate for the hydrogenation of butyraldehyde was observed over the $\mathrm{PdCu}_{3} / \mathrm{SiO}_{2}$ catalyst, the ethanol consumption rate was highest for the $\mathrm{PdCu}_{3} / \mathrm{SiO}_{2}$ catalyst; this is due to the rate-determining step being the ethanol dehydrogenation, which takes place over the metal catalyst [9].

Moreover, the selectivity of the two reactions follows the same patterns. There is one exception to this pattern: the selectivity of the $\mathrm{PdCu}_{3} / \mathrm{SiO}_{2}$ catalyst is higher than that of the monometallic $\mathrm{Cu} / \mathrm{SiO}_{2}$ catalyst. This selectivity difference is due to the extensive formation of esters over the $\mathrm{Cu} / \mathrm{SiO}_{2}$ catalyst during the ethanol Guerbet reaction, via a hemiacetal dehydrogenation pathway that occurs via a C-O bond formation step between an alcohol and an aldehyde over $\mathrm{TiO}_{2}$ [13]. We attribute the suppression of ester formation over the $\mathrm{Cu}$ to the electronic exchange with $\mathrm{Pd}$ and the promotional effects of $\mathrm{Pd}$ on the $\mathrm{Cu}$ sites. We believe that the shift of the $\mathrm{d}$-band center of $\mathrm{Cu}$ renders it less capable of dehydrogenating the reactive hemiacetals to esters.

All these observations together suggest a synergistic effect between $\mathrm{Pd}$ and $\mathrm{Cu}$, where $\mathrm{Pd}$ is capable of electronically promoting $\mathrm{Cu}$, leading to an increased rate of alcohol dehydrogenation and suppression of hemiacetal dehydrogenation. At the same time, the isolation of the Pd sites results in the absence of Pd$\mathrm{Pd}$ ensembles and the almost-complete suppression of decarbonylation. Both of these effects result in the promise of a $\mathrm{PdCu}_{3} / \mathrm{SiO}_{2}$ catalyst as an ethanol Guerbet catalyst, in conjunction with a $\mathrm{TiO}_{2} \mathrm{CO}-$ catalyst. 


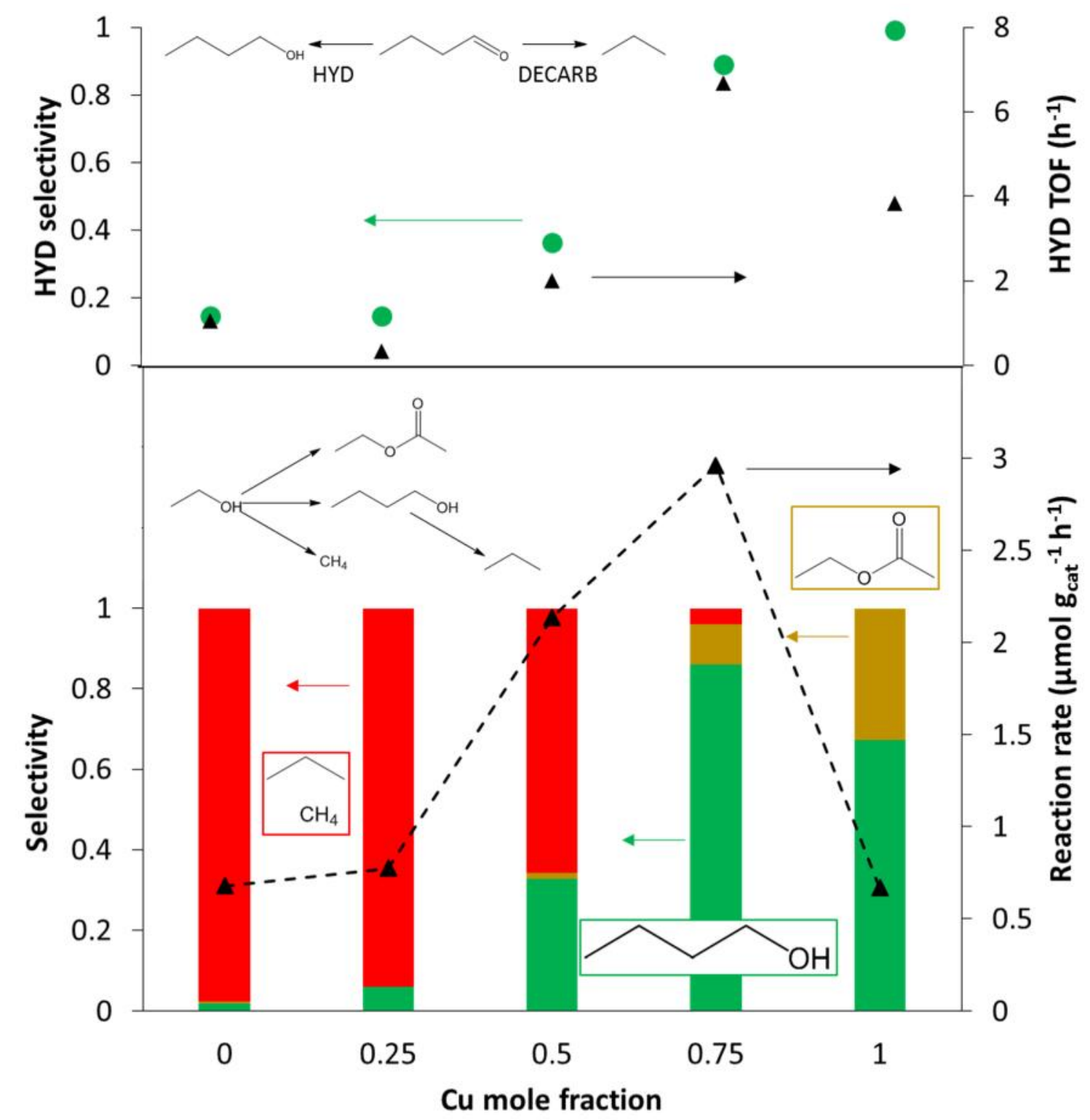

\section{$\mathrm{C} 4+$ products Ethyl acetate $=$ Light gases $-\mathbf{\Lambda}$-Reaction rate}

Figure 8: Effects of Cu mole fraction on ethanol Guerbet reaction rate and selectivity. $523 \mathrm{~K}, 10 \mathrm{kPa}$ EtOH, balance $\mathrm{H}_{2}, 1: 4$ by mass $\mathrm{PdCu} / \mathrm{SiO}_{2}$ catalyst to $\mathrm{TiO}_{2}$ co catalyst. 8-12\% conversion.

\section{Conclusions}

In this work, we use $\mathrm{PdCu}$ and $\mathrm{PdAg}$ catalysts supported on $\mathrm{SiO}_{2}$ to investigate the effects of alloying on the conversion of simple short-chain oxygenates, butyraldehyde and ethanol, using a combination of kinetic experiments, first principles calculations, and X-ray absorption measurements. We show that ligand and ensemble effects of $\mathrm{Pd}-\mathrm{Cu}$ alloying result in significant changes in the reactivity and selectivity of the catalyst. First, the disruption of Pd-Pd surface ensembles by $\mathrm{Cu}$ atoms results in the suppression of butyraldehyde decarbonylation. Electronic effects, investigated by Pd $\mathrm{L}_{\text {III }}$ XANES and DFT, show charge transfer from $\mathrm{Cu}$ to $\mathrm{Pd}$ and a large upshift of the d-band center of $\mathrm{Cu}$ towards the Fermi energy. This 
results in the formation of a new, selective active site, a Pd-promoted Cu surface, manifested in the increased reaction rate for hydrogenation, reaching a maximum over a $\mathrm{PdCu}_{3} / \mathrm{SiO}_{2}$ sample.

Alloying of $\mathrm{Pd}$ and $\mathrm{Ag}$ results in minimal selectivity changes, as reaction rates decrease for both hydrogenation and decarbonylation reactions. The weaker electronic interaction, quantified by DFT and demonstrated by Pd $\mathrm{L}_{\text {III }}$ XANES experiments, results in no significant promotion of Pd by alloying with $\mathrm{Ag}$. Consistent with our findings for $\mathrm{Cu}$, Pd does lift the deep-lying $d$-band center of $\mathrm{Ag}$, but not enough to instill any reactivity into $\mathrm{Ag}$. Thus, the drop in reaction rates with increasing $\mathrm{Ag}$ content is due to the loss of $P d$ sites on the surface.

The practical implications of these results are demonstrated in the Guerbet reaction of ethanol over $\mathrm{PdCu} / \mathrm{SiO}_{2}$ catalysts in a physical mixture with $\mathrm{TiO}_{2}$. By adjusting the atomic ratio, the best performance was achieved by a Pd-promoted Cu-rich $\mathrm{PdCu}_{3} / \mathrm{SiO}_{2}$ catalyst. The presence of $\mathrm{Cu}$ disrupts the Pd-Pd ensembles responsible for undesirable decarbonylation reactions, while $\mathrm{Pd}$ promotes $\mathrm{Cu}$, resulting in higher reaction rates and prevention of $\mathrm{Cu}$-catalyzed esterification.

\section{Acknowledgements}

Startup funds from Oregon State University are gratefully acknowledged for the support of TB, TP and SRS. YL and LCG acknowledge financial support from the National Science Foundation (NSF) under award number 1454384. Portions of this work were performed at the DuPont-Northwestern-Dow Collaborative Access Team (DND-CAT) located at Sector 5 of the Advanced Photon Source (APS). DND-CAT is supported by Northwestern University, E.I. DuPont de Nemours \& Co., and The Dow Chemical Company. Portions of this work were performed at Sector 9 of the Advanced Photon Source (APS). This research used resources of the APS, a DOE Office of Science (DOE-SC) user facility operated for DOE-SC by Argonne National Laboratory under Contract No. DE-AC02-06CH11357. Portions of this work were performed on instrumentation supported by the National Science Foundation via the Major Research Instrumentation (MRI) Program under Grant No. 1040588 and 1531814. We also gratefully acknowledge financial support for the acquisition of the TEM instrument form the Murdock Charitable Trust and the Oregon Nanoscience and Microtechnologies Institute (ONAMI). Computational work used the Extreme Science and Engineering Discovery Environment (XSEDE) [52], supported by NSF grant number ACl1053575, as well as resources provided by the Research Computing Data Core at the University of Houston.

\section{References}

1. Sun, Z. and K. Barta, Cleave and couple: toward fully sustainable catalytic conversion of lignocellulose to value added building blocks and fuels. Chemical Communications, 2018. 54(56): p. 7725-7745.

2. Gabriëls, D., et al., Review of catalytic systems and thermodynamics for the Guerbet condensation reaction and challenges for biomass valorization. Catalysis Science \& Technology, 2015. 5(8): p. 3876-3902.

3. Pham, T.N., D. Shi, and D.E. Resasco, Kinetics and Mechanism of Ketonization of Acetic Acid on Ru/TiO2 Catalyst. Topics in Catalysis, 2014. 57(6): p. 706-714.

4. Pham, T.N., et al., Ketonization of Carboxylic Acids: Mechanisms, Catalysts, and Implications for Biomass Conversion. ACS Catalysis, 2013. 3(11): p. 2456-2473. 
5. Gangadharan, A., et al., Condensation reactions of propanal over CexZr1-xO2 mixed oxide catalysts. Applied Catalysis A: General, 2010. 385(1): p. 80-91.

6. Eagan, N.M., et al., Catalytic synthesis of distillate-range ethers and olefins from ethanol through Guerbet coupling and etherification. Green Chemistry, 2019. 21(12): p. 3300-3318.

7. Moteki, T. and D.W. Flaherty, Mechanistic Insight to C-C Bond Formation and Predictive Models for Cascade Reactions among Alcohols on Ca- and Sr-Hydroxyapatites. ACS Catalysis, 2016. 6(7): p. 4170-4183.

8. Li, H., et al., Carbon-Increasing Catalytic Strategies for Upgrading Biomass into Energy-Intensive Fuels and Chemicals. ACS Catalysis, 2018. 8(1): p. 148-187.

9. Goulas, K.A., et al., ABE Condensation over Monometallic Catalysts: Catalyst Characterization and Kinetics. ChemCatChem, 2017. 9(4): p. 677-684.

10. Pino, N., et al., Structure, activity, and selectivity of bimetallic $\mathrm{Pd}-\mathrm{Fe} / \mathrm{SiO} 2$ and $\mathrm{Pd}-\mathrm{Fe} / \mathrm{V}-\mathrm{Al} / 2 \mathrm{O} 3$ catalysts for the conversion of furfural. Journal of Catalysis, 2017. 350: p. 30-40.

11. Sun, Z., et al., Efficient Catalytic Conversion of Ethanol to 1-Butanol via the Guerbet Reaction over Copper- and Nickel-Doped Porous. ACS Sustainable Chemistry \& Engineering, 2017. 5(2): p. 1738-1746.

12. Marcu, I.-C., et al., Catalytic valorization of bioethanol over Cu-Mg-Al mixed oxide catalysts. Catalysis Today, 2009. 147(3): p. 231-238.

13. Wang, S., K. Goulas, and E. Iglesia, Condensation and esterification reactions of alkanals, alkanones, and alkanols on TiO2: Elementary steps, site requirements, and synergistic effects of bifunctional strategies. Journal of Catalysis, 2016. 340: p. 302-320.

14. Hilmen, A.-M., et al., Synthesis of higher alcohols on copper catalysts supported on alkalipromoted basic oxides. Applied Catalysis A: General, 1998. 169(2): p. 355-372.

15. Subramaniam, S., et al., Direct Catalytic Conversion of Ethanol to C5+ Ketones: Role of Pd-Zn Alloy on Catalytic Activity and Stability. Angewandte Chemie International Edition, 2020. 59(34): p. $14550-14557$.

16. Wang, C., et al., A comparison of furfural hydrodeoxygenation over Pt-Co and Ni-Fe catalysts at high and low H2 pressures. Catalysis Today, 2018. 302: p. 73-79.

17. Rao Peela, N., et al., Core-Shell Nanocatalyst Design by Combining High-Throughput Experiments and First-Principles Simulations. ChemCatChem, 2013. 5(12): p. 3712-3718.

18. Snåre, M., et al., Catalytic deoxygenation of unsaturated renewable feedstocks for production of diesel fuel hydrocarbons. Fuel, 2008. 87(6): p. 933-945.

19. Goulas, K., et al., Selectivity Tuning over Monometallic and Bimetallic Dehydrogenation Catalysts: Effects of Support and Particle Size. Catalysis Science \& Technology, 2017. 8.

20. Sitthisa, S., et al., Conversion of furfural and 2-methylpentanal on $\mathrm{Pd} / \mathrm{SiO} 2$ and $\mathrm{Pd}-\mathrm{Cu} / \mathrm{SiO} 2$ catalysts. Journal of Catalysis, 2011. 280(1): p. 17-27.

21. Yu, W., M.D. Porosoff, and J.G. Chen, Review of Pt-Based Bimetallic Catalysis: From Model Surfaces to Supported Catalysts. Chemical Reviews, 2012. 112(11): p. 5780-5817.

22. Ma, Z., et al., Overview of catalyst application in petroleum refinery for biomass catalytic pyrolysis and bio-oil upgrading. RSC Advances, 2015. 5(107): p. 88287-88297.

23. Grabow, L., Y. Xu, and M. Mavrikakis, Lattice strain effects on CO oxidation on Pt(111). Physical Chemistry Chemical Physics, 2006. 8(29): p. 3369-3374.

24. Yuan, Q., et al., Finite Size Effects in Submonolayer Catalysts Investigated by CO Electrosorption on Pt(sML)/Pd(100). J Am Chem Soc, 2017. 139(39): p. 13676-13679.

25. Guo, S., et al., Insights into Nitrate Reduction over Indium-Decorated Palladium Nanoparticle Catalysts. ACS Catalysis, 2018. 8(1): p. 503-515. 
26. Kresse, G. and J. Furthmüller, Efficiency of ab-initio total energy calculations for metals and semiconductors using a plane-wave basis set. Computational Materials Science, 1996. 6(1): $p$. 15-50.

27. Kresse, G. and J. Hafner, Ab initio molecular dynamics for open-shell transition metals. Physical Review B, 1993. 48(17): p. 13115-13118.

28. Kresse, G. and J. Furthmüller, Efficient iterative schemes for ab initio total-energy calculations using a plane-wave basis set. Physical Review B, 1996. 54(16): p. 11169-11186.

29. Bahn, S.R. and K.W. Jacobsen, An object-oriented scripting interface to a legacy electronic structure code. Computing in Science \& Engineering, 2002. 4(3): p. 56-66.

30. Kresse, G. and D. Joubert, From ultrasoft pseudopotentials to the projector augmented-wave method. Physical Review B, 1999. 59(3): p. 1758-1775.

31. Blöchl, P.E., Projector augmented-wave method. Physical Review B, 1994. 50(24): p. 1795317979.

32. Perdew, J.P. and Y. Wang, Accurate and simple analytic representation of the electron-gas correlation energy. Physical Review B, 1992. 45(23): p. 13244-13249.

33. Monkhorst, H.J. and J.D. Pack, Special points for Brillouin-zone integrations. Physical Review B, 1976. 13(12): p. 5188-5192.

34. Stevens, E.D., J. Rys, and P. Coppens, Quantitative comparison of theoretical calculations with the experimentally determined electron density distribution of formamide. Journal of the American Chemical Society, 1978. 100(8): p. 2324-2328.

35. Gillan, M.J., Calculation of the vacancy formation energy in aluminium. Journal of Physics: Condensed Matter, 1989. 1(4): p. 689-711.

36. Bengtsson, L., Dipole correction for surface supercell calculations. Physical Review B, 1999. 59(19): p. 12301-12304.

37. Anbarasan, P., et al., Integration of chemical catalysis with extractive fermentation to produce fuels. Nature, 2012. 491(7423): p. 235-239.

38. Kozlowski, J.T. and R.J. Davis, Heterogeneous Catalysts for the Guerbet Coupling of Alcohols. ACS Catalysis, 2013. 3(7): p. 1588-1600.

39. Quesada, J., et al., Tuning the selectivities of $\mathrm{Mg}-\mathrm{Al}$ mixed oxides for ethanol upgrading reactions through the presence of transition metals. Applied Catalysis A: General, 2018. 559: p. 167-174.

40. Quesada, J., et al., Enhancement of the 1-butanol productivity in the ethanol condensation catalyzed by noble metal nanoparticles supported on Mg-Al mixed oxide. Applied Catalysis A: General, 2018. 563: p. 64-72.

41. Goulas, K.A., et al., Synergistic Effects in Bimetallic Palladium-Copper Catalysts Improve Selectivity in Oxygenate Coupling Reactions. Journal of the American Chemical Society, 2016. 138(21): p. 6805-6812.

42. Goulas, K.A., et al., Selectivity tuning over monometallic and bimetallic dehydrogenation catalysts: effects of support and particle size. Catalysis Science \& Technology, 2018. 8(1): p. 314327.

43. Ball, M.R., et al., AgPd and CuPd Catalysts for Selective Hydrogenation of Acetylene. ACS Catalysis, 2020: p. 8567-8581.

44. Witjens, L.C., et al., Pd L3 edge XANES investigation of the electronic and geometric structure of Pd/Ag-H membranes. Physical Chemistry Chemical Physics, 2004. 6(14): p. 3903-3906.

45. Shimizu, K.-i., et al., The average Pd oxidation state in Pd/SiO2 quantified by L3-edge XANES analysis and its effects on catalytic activity for $\mathrm{CO}$ oxidation. Catalysis Science \& Technology, 2012. 2(4): p. 767-772. 
46. Simakova, I., et al., Deoxygenation of palmitic and stearic acid over supported Pd catalysts: Effect of metal dispersion. Applied Catalysis A: General, 2009. 355(1): p. 100-108.

47. Kitchin, J.R., et al., Role of Strain and Ligand Effects in the Modification of the Electronic and Chemical Properties of Bimetallic Surfaces. Physical Review Letters, 2004. 93(15): p. 156801.

48. Tew, M.W., J.T. Miller, and J.A. van Bokhoven, Particle Size Effect of Hydride Formation and Surface Hydrogen Adsorption of Nanosized Palladium Catalysts: L3 Edge vs K Edge X-ray Absorption Spectroscopy. The Journal of Physical Chemistry C, 2009. 113(34): p. 15140-15147.

49. Piernavieja-Hermida, M., et al., Towards ALD thin film stabilized single-atom Pd1 catalysts. Nanoscale, 2016. 8(33): p. 15348-15356.

50. Quesada, J., et al., Effect of Au nanoparticles on the activity of TiO2 for ethanol upgrading reactions. Applied Catalysis A: General, 2018. 551: p. 23-33.

51. Goulas, K.A., et al., X-ray tomography measurements identify structure-reactivity correlations in catalysts for oxygenates coupling reactions. Catalysis Today, 2019. 336: p. 186-192.

52. Towns, J., et al., XSEDE: Accelerating Scientific Discovery. Computing in Science \& Engineering, 2014. 16(5): p. 62-74. 